\title{
Clinical Neuroanatomy and Neurotransmitter-Mediated Regulation of Penile Erection
}

\author{
Junyang Jung, Hyun Woo Jo, Hyunseob Kwon'1, Na Young Jeong² \\ Department of Anatomy and Neurobiology, Biomedical Science Institution, Kyung Hee University School of Medicine, Seoul; \\ ${ }^{1}$ Department of Pediatrics, Inje University Haeundae Paik Hospital, Busan; \\ ${ }^{2}$ Department of Anatomy and Cell Biology, Dong-A University College of Medicine, Busan, Korea
}

\begin{abstract}
Erectile dysfunction (ED) has an adverse impact on men's quality of life. Penile erection, which is regulated by nerves that are innervated into the erectile tissue, can be affected by functional or anatomical trauma of the perineal region, including specific structures of the penis, causing ED. Penile erection is neurologically controlled by the autonomic nervous system. Therefore, it is of utmost importance to understand the neurogenic structure of the erectile tissue and the types of neurotransmitters involved in the penile erection process. Here, we highlight the basic clinical anatomy and erectile function of the penis. Understanding the clinical connotation of the relationship between penile erectile structure and function may provide fresh insights for identifying the main mechanisms involved in ED and help develop surgical techniques for the treatment of ED.
\end{abstract}

Keywords: Penile erection; Neurotransmitter; Parasympathetic nervous system; Erectile dysfunction

\section{INTRODUCTION}

Penile erection describes the ability of men to maintain sufficient penile rigidity so that satisfactory sexual intercourse is achieved. Hemodynamic events in the erectile tissues, such as alterations in blood flow to the cavernous spaces of the penis, influence erection. Upon sexual stimulation and sexual arousal, parasympathetic activity leads to penile arterial dilatation and subsequently causes relaxation of the erectile smooth muscles of the corpora cavernosa [1,2]. Through the dilated vessels, blood fills the sinusoids and the ischiocavernosus and bulbospongiosus muscles, causing restriction of the venous outflow from the corpora cavernosa $[1,2]$.

Penile erection involves a complex interaction among the components of the peripheral nerves. The different penile structures receive autonomic (sympathetic and parasympathetic), so- matic, and sensory innervations [2]. The autonomically innervated corpora cavernosa is composed of numerous nerve terminals, such as adrenergic, cholinergic, nonadrenergic, and noncholinergic innervations, and numerous neurotransmitters, such as acetylcholine, norepinephrine [3-5], adenosine 5'-triphosphate (ATP) [6-8], and nitric oxide (NO) [9-13]. The neurotransmitters released from the cavernous nerve terminals, as well as from the endothelial cells of the penis, have vasodilator properties and act to relax the arteries that supply the erectile tissue. Contraction of erectile smooth muscles occurs via interruption of neurotransmitter release and induces the trapped blood to flow out of the erectile tissue, which results in penis detumescence.

Acute or chronic perineal injuries have been reported to induce erectile dysfunction (ED) [14-17]. Therefore, understanding the anatomy of the male external genital organ and the neurogenic mechanisms involved in penile erection is of practical
Corresponding author: Junyang Jung

Department of Anatomy and Neurobiology, Kyung Hee University School of Medicine, 26 Kyungheedae-ro, Dongdaemun-gu, Seoul 130-701, Korea Tel: +82-2-961-2303 / Fax: +82-2-969-6958 / E-mail: jjung@khu.ac.kr
This is an Open Access article distributed under the terms of the Creative Commons Attribution Non-Commercial License (http://creativecommons.org/licenses/by-nc/3.0/) which permits unrestricted non-commercial use, distribution, and reproduction in any medium, provided the original work is properly cited. 
importance for the treatment of ED. This brief review focuses on the anatomical basis of penile erection, with special emphasis on its neurogenic components.

\section{ANATOMY OF THE MALE EXTERNAL GENITAL ORGAN}

The human penis is the male external genital and copulatory organ and performs dual functions: semen ejaculation and urination. The penis is composed of three cavernosal bodies: the single corpus spongiosum (a mass of spongy tissue surrounding the urethra) and two paired corpora cavernosa. The corpus spongiosum and the corpora cavernosa are positioned in the ventral and dorsal regions of the penis, respectively. Each cavernosal body is encapsulated by the tunica albuginea and the three encapsulated cavernosal bodies are surrounded by deep penile fascia.

Arterial blood supply into the penis is mainly provided by three branches of the internal pudendal artery. Blood to the corpora cavernosa is supplied by the dorsal arteries of the penis, which run along each side of the deep dorsal vein, and by the deep arteries of the penis, located in the center of the corpora cavernosa. Blood to the corpus spongiosum is supplied by the dorsal arteries and by the arteries of the bulb of the penis, which are positioned in the bulbous part of the corpus spongiosum. Numerous branches of the deep arteries (called helicine arteries) spread into the cavernous spaces and supply blood to the penile erectile tissue, mediating the erection of the penis. In the relaxed penis, blood supply into the cavernous spaces is restricted and helicine arteries become coiled.

\section{INNERVATION OF THE CAVERNOUS SPACES}

Penile erection is neurologically controlled by the sympathetic and parasympathetic systems. The penis is innervated by nerves originated from the S2-S4 nerve roots. When the prevertebral plexus enters the pelvic region, it forms the hypogastric nerves. These nerves are situated medial to the internal iliac vessels and pass through the pelvic inlet. The pelvic plexuses (also called inferior hypogastric plexuses) are formed by the joining of the hypogastric nerves and the pelvic splanchnic nerves, which arise from sacral spinal nerves S2-S4 to provide parasympathetic innervation. Sympathetic and parasympathetic fibers enter the pelvic plexus and their input is integrated in the penis. The prostatic plexus is formed by branches of the pelvic plexus- es crossing the deep perineal pouch. Cavernous nerves arise from the prostatic plexus and carry parasympathetic fibers, innervating the helicine arteries of the erectile tissue in the cavernous spaces. The cavernous nerves generally mediate vasodilation and stimulate the erection of the penis.

In addition, the smooth muscle tone of the fibrous trabeculae is regulated by the sympathetic and parasympathetic systems of the autonomic nervous system. The sympathetic fibers from the hypogastric plexuses and sacral splanchnic nerves keep the cavernous smooth muscle in a contracted state and mediate the detumescence of the penis. In contrast, parasympathetic fibers from the S2-S4 anterior roots keep the cavernous smooth muscle in the erected state and mediate the tumescence of the penis.

\section{PENILE ERECTION}

Penile erection is triggered by sexual stimulation and sexual arousal. Parasympathetic stimulation via the cavernous nerves initiates the process, causing the coiled helicine arteries to uncoil (by expansion of their lumen), relaxing the smooth muscle in the trabeculae [1,2]. As a consequence, blood flows into the empty cavernous spaces causing the cavernous spaces of the penis to dilate, the corpora cavernosa is more dilated than the corpora spongiosum $[1,2]$. During the erectile process, the ischiocavernosus and bulbospongiosus muscles mechanically compress the veins of the corpora cavernosa, restricting the return of blood flow to the venous system [1,2]. Without venous blood drainage, the corpora cavernosa and corpus spongiosum become rigid, maintaining the erection of the penis.

\section{NEUROTRANSMITTERS AND ERECTION}

The nerves and endothelial cells of sinusoids and blood vessels in the cavernous spaces release transmitters. These transmitters interact with the smooth muscles in the cavernous spaces and mediate the vasodilation and relaxation of the corpora cavernosa, leading to penile erection. Several neurotransmitters are well-known regulators of penile erection, for example, neurotransmitters secreted by nonadrenergic and noncholinergic nerves, norepinephrine, and acetylcholine.

\section{Nitrergic Innervation}

The localization of nitrergic nerves in the penis has been reported in several studies. Neuronal NO synthase (nNOS), which synthesizes neural-derived NO, was found in the pelvic plexus, 
dorsal penile nerve, and cavernous nerves that branch into the erectile tissue $[18,19]$. In rat, nitrergic nerves originate from the pelvic ganglion [20-22]. These nerves were also found in preganglionic neurons in the intermediolateral column at the spinal cold levels T11-L3 and in dorsal root ganglions [23]. The presence of nNOS-positive nerves in erectile tissue provides morphological evidence that $\mathrm{NO}$ acts as a modulator of penile erection.

\section{Cholinergic Innervation}

The importance of the parasympathetic system in the regulation of penile erection is well known [2]. Cholinergic nerves in the human corpora cavernosa form acetylcholine and release it [24]. The human corpora cavernosa and penile vasculature are densely innervated by cholinergic nerves and contain a high density of acetylcholine-esterase [25-27]. In the rat, choline acetyltransferase or the vesicular acetylcholine transporter (VAChT) are found in the major pelvic plexus, penile arteries and corpora cavernosa $[19,28]$. VAChT-positive cholinergic innervation is also densely found in human erectile tissue [19]. As cholinergic activity is not equivalent to parasympathetic activity, cholinergic nerves are likely to influence penile erection indirectly (e.g., by mediating nonadrenergic noncholinergic nerves function in the vasodilation of erectile tissue) [24].

\section{Purinergic Innervation}

In arteries in general, the ATP released from nerve terminals functions to regulate vascular tone: (1) it has vasodilator activity via P2Y purinoceptors; and (2) it has vasoconstrictor activity via P2X purinoceptors [29-31]. Purinergic receptors are also present in the male external genital organ, where they regulate penile erection. In rats, $\mathrm{P} 2 \mathrm{Y} 1$ receptors have been identified in endothelial cells, which line the lacunar space and blood vessels in the penis [32]. In rabbits, P2Y4 receptors have been found in smooth muscle, which is relaxed by the ATP released from purinergic nerves [9,33]. Similarly, in human corpora cavernosa, ATP induces relaxation of corporal smooth muscles to the same extent as NO does [6,34]. Therefore, ATP released from purinergic nerve endings mediates the relaxation of vessels in the penis and regulates penile erection.

\section{URINATION AND EJACULATION}

Ejaculation occurs when a man reaches orgasm and is regulated by autonomic and somatic responses. During ejaculation, se- men is expelled from the body though the urethra. A parasympathetic response causes the contraction of the urethral muscle during ejaculation $[35,36]$. The pudendal nerves also control the contraction of the bulbospongiosus muscles and affect the rhythmical ejection of seminal fluid from the urethra during ejaculation [37,38]. During ejaculation, the internal urethral sphincter (IUS) prevents voiding. The IUS lies at the inferior end of the bladder and proximal end of the urethra (preprostatic urethra). The tonic contraction of the IUS is under the control of the sympathetic nervous system $[35,39]$ and prevents the reflux of seminal fluid into the urinary bladder and the mixing of urine and seminal fluid [40].

\section{CONCLUSIONS}

Nerves distributed throughout the penile erectile tissue regulate erection. Many common neurological disorders are related to nervous activity disturbances. Studying the roles played by the cholinergic, purinergic and nitrergic innervations and their corresponding neurotransmitters is essential to understand the physiology of penile erection and the pathophysiology of ED. In men, ED adversely affects quality of life. Therefore, further research into the clinical and functional anatomy of the erectile structure of the penis will be crucial to improve men's physical and psychological health.

\section{CONFLICT OF INTEREST}

No potential conflict of interest relevant to this article was reported.

\section{ACKNOWLEDGEMENTS}

This work was supported by Dong-A University research fund.

\section{REFERENCES}

1. Azadzoi KM, Vlachiotis J, Pontari M, Siroky MB. Hemodynamics of penile erection: III. Measurement of deep intracavernosal and subtunical blood flow and oxygen tension. J Urol 1995;153:521-6.

2. Andersson KE, Wagner G. Physiology of penile erection. Physiol Rev 1995;75:191-236.

3. Bitran D, Hull EM. Pharmacological analysis of male rat sexual behavior. Neurosci Biobehav Rev 1987;11:365-89.

4. Giuliano F, Rampin O. Alpha receptors in the central nervous sys- 
tem and its effects on erection. J Androl 1999;20:683-7.

5. Aragona F, Panza N, Mangano A, Castellucci E, Capizzi A. No evidence of fluid absorption during continuous low-pressure transurethral resection of the prostate: assessment by measuring expiratory breath ethanol concentrations. Eur Urol 1999;36:103-6.

6. Levin RM, Hypolite JA, Broderick GA. Comparison of the pharmacological response of human corpus cavernosal tissue with the response of rabbit cavernosal tissue. Gen Pharmacol 1995;26:1107-11.

7. Tong YC, Broderick G, Hypolite J, Levin RM. Correlations of purinergic, cholinergic and adrenergic functions in rabbit corporal cavernosal tissue. Pharmacology 1992;45:241-9.

8. Wu HY, Broderick GA, Suh JK, Hypolite JA, Levin RM. Effects of purines on rabbit corpus cavernosum contractile activity. Int J Impot Res 1993;5:161-7.

9. Melis MR, Argiolas A. Role of central nitric oxide in the control of penile erection and yawning. Prog Neuropsychopharmacol Biol Psychiatry 1997;21:899-922.

10. Lorrain DS, Matuszewich L, Howard RV, Du J, Hull EM. Nitric oxide promotes medial preoptic dopamine release during male rat copulation. Neuroreport 1996;8:31-4.

11. Melis MR, Succu S, Mauri A, Argiolas A. Nitric oxide production is increased in the paraventricular nucleus of the hypothalamus of male rats during non-contact penile erections and copulation. Eur J Neurosci 1998;10:1968-74.

12. Sato Y, Horita H, Kurohata T, Adachi H, Tsukamoto T. Effect of the nitric oxide level in the medial preoptic area on male copulatory behavior in rats. Am J Physiol 1998;274(1 Pt 2):R243-7.

13. Sato Y, Christ GJ, Horita H, Adachi H, Suzuki N, Tsukamoto T. The effects of alterations in nitric oxide levels in the paraventricular nucleus on copulatory behavior and reflexive erections in male rats. J Urol 1999;162:2182-5.

14. Carr LK, Webster GD. Genitourinary trauma. Curr Opin Urol 1996;6:140-3.

15. Cass AS. Urethral injury in the multiple-injured patient. J Trauma 1984;24:901-6.

16. Pokorny M, Pontes JE, Pierce JM Jr. Urological injuries associated with pelvic trauma. J Urol 1979;121:455-7.

17. Sandler CM, Hall JT, Rodriguez MB, Corriere JN Jr. Bladder injury in blunt pelvic trauma. Radiology 1986;158:633-8.

18. Burnett AL, Tillman SL, Chang TS, Epstein JI, Lowenstein CJ, Bredt DS, et al. Immunohistochemical localization of nitric oxide synthase in the autonomic innervation of the human penis. J Urol 1993;150:73-6.

19. Hedlund P, Ny L, Alm P, Andersson KE. Cholinergic nerves in human corpus cavernosum and spongiosum contain nitric oxide synthase and heme oxygenase. J Urol 2000;164(3 Pt 1):868-75.

20. Dail WG, Barba V, Leyba L, Galindo R. Neural and endothelial nitric oxide synthase activity in rat penile erectile tissue. Cell Tissue Res 1995;282:109-16.

21. Domoto T, Tsumori T. Co-localization of nitric oxide synthase and vasoactive intestinal peptide immunoreactivity in neurons of the major pelvic ganglion projecting to the rat rectum and penis. Cell Tissue Res 1994;278:273-8.

22. Vizzard MA, Erdman SL, Forstermann U, de Groat WC. Differential distribution of nitric oxide synthase in neural pathways to the urogenital organs (urethra, penis, urinary bladder) of the rat. Brain Res 1994;646:279-91.

23. Vanhatalo S, Klinge E, Sjostrand NO, Soinila S. Nitric oxide-synthesizing neurons originating at several different levels innervate rat penis. Neuroscience 1996;75:891-9.

24. Saenz de Tejada I, Blanco R, Goldstein I, Azadzoi K, de las Morenas A, Krane RJ, et al. Cholinergic neurotransmission in human corpus cavernosum. I. Responses of isolated tissue. Am J Physiol 1988;254(3 Pt 2):H459-67.

25. McConnell J, Benson GS. Innervation of human penile blood vessels. Neurourol Urodyn 1982;1:199-210

26. Stief C, Benard F, Bosch R, Aboseif S, Nunes L, Lue TF, et al. Acetylcholine as a possible neurotransmitter in penile erection. J Urol 1989;141:1444-8.

27. Costa P, Soulie-Vassal ML, Sarrazin B, Rebillard X, Navratil H, Bali JP. Adrenergic receptors on smooth muscle cells isolated from human penile corpus cavernosum. J Urol 1993;150:859-63.

28. Dail WG, Hamill RW. Parasympathetic nerves in penile erectile tissue of the rat contain choline acetyltransferase. Brain Res 1989; 487:165-70.

29. Burnstock G, Kennedy C. A dual function for adenosine 5'-triphosphate in the regulation of vascular tone. Excitatory cotransmitter with noradrenaline from perivascular nerves and locally released inhibitory intravascular agent. Circ Res 1986;58:319-30.

30. Burnstock G. Historical review: ATP as a neurotransmitter. Trends Pharmacol Sci 2006;27:166-76.

31. Burnstock G. Discovery of purinergic signalling, the initial resistance and current explosion of interest. Br J Pharmacol 2012;167: 238-55.

32. Obara K, Lepor H, Walden PD. Localization of P2Y1 purinoceptor transcripts in the rat penis and urinary bladder. J Urol 1998;160: 587-91.

33. Calvert RC, Khan MA, Thompson CS, Mikhailidis DP, Burnstock G. A functional study of purinergic signalling in the normal and pathological rabbit corpus cavernosum. BJU Int 2008;101:1043-7. 
34. Hupertan V, Neuzillet Y, Stucker O, Pons C, Leammel E, Lebret T. Effects of nucleotides adenosine monophosphate and adenosine triphosphate in combination with $\mathrm{L}$-arginine on male rabbit corpus cavernosum tissue. Int J Androl 2012;35:860-6.

35. Berne RM, Levy MN, Koeppen BM, Stanton BA. Berne \& Levy physiology. Philadelphia: Elsevier/Mosby; 2008.

36. Chancellor MB, Yoshimura N. Neurophysiology of stress urinary incontinence. Rev Urol 2004;6 Suppl 3:S19-28.

37. Boron WF, Boulpaep EL. Medical physiology: a cellular and mo- lecular approach. Philadelphia: Elsevier/Saunders; 2005.

38. Roberts KP, Pryor JL. Anatomy and physiology of the male reproductive system. In: Hellstrom WJ. Male infertility and sexual dysfunction. New York: Springer; 1997. p. 1-21.

39. de Groat WC, Theobald RJ. Reflex activation of sympathetic pathways to vesical smooth muscle and parasympathetic ganglia by electrical stimulation of vesical afferents. J Physiol 1976;259:223-37.

40. Shafik A. Pelvic floor muscles and sphincters during erection and ejaculation. Arch Androl 1997;39:71-8. 